Alma Mater Studiorum - Università di Bologna DEPARTMENT OF ECONOMICS

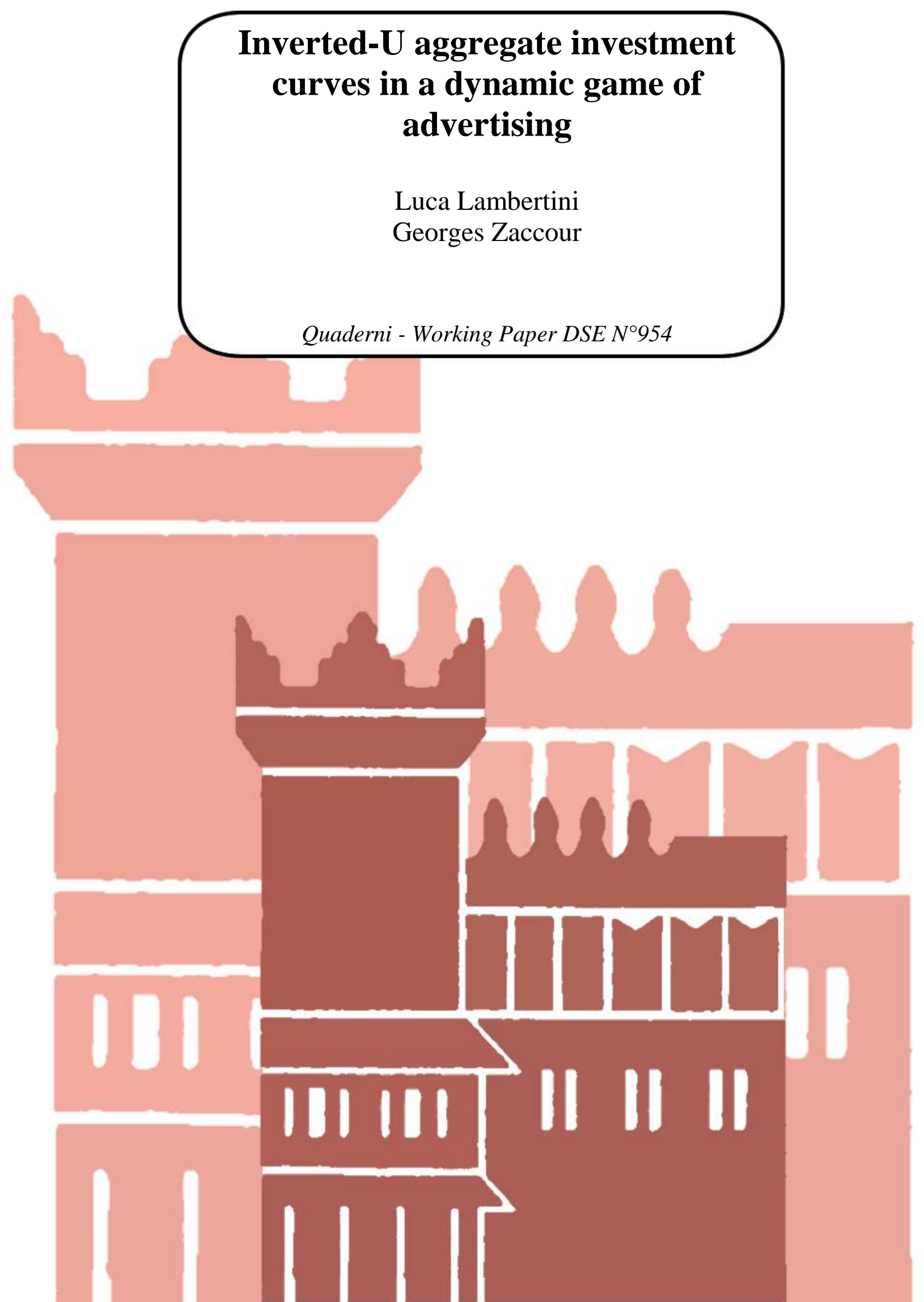




\title{
Inverted-U aggregate investment curves in a dynamic game of advertising
}

\author{
Luca Lambertini \\ Department of Economics, University of Bologna \\ Strada Maggiore 45, 40125 Bologna, Italy \\ luca.lambertini@unibo.it \\ Georges Zaccour \\ GERAD, HEC Montréal \\ 3000, chemin de la Côte-Sainte-Catherine \\ Montréal (Québec) Canada H3T 2A7 \\ georges.zaccour@gerad.ca
}

July 4, 2014

\begin{abstract}
We revisit the relationship between market power and firms' investment incentives in a noncooperative differential oligopoly game in which firms sell differentiated goods and invest in advertising to increase the brand equity of their respective goods. The feedback equilibrium obtains under open-loop rules, and aggregate expenditure on goodwill takes an inverted-U shape under both Cournot and Bertrand behaviour, provided product differentiation is sufficiently high. Total industry expenditure is higher under Cournot competition.
\end{abstract}

Keywords: Goodwill; Oligopoly; Advertising; Differential games; Schumpeterian hypothesis.

JEL Codes: C73, L13, M37 


\section{Introduction}

The acquired industrial organization approach to the bearings of market power on the size and pace of technical progress can be traced back to the indirect debate between Schumpeter $(1934,1942)$ and Arrow (1962) on the socalled Schumpeterian hypothesis, which, in a nutshell, says that one should expect to see a direct relationship between innovation and market power or industry concentration. Consequently, Schumpeter's claim is that one should expect to observe the highest R\&D effort under monopoly. The well known counter-argument formulated by Arrow is that a monopolist, being affected by a replacement effect, might rest on his laurels, being thus outperformed along the R\&D dimension by any form of even slightly more competitive industry. An analogous, although not entirely equivalent version of the Arrow-Schumpeter debates relies on the relationship between firms' investment incentives and the intensity of competition rather than industry structure. In this perspective, the Schumpeterian stance is that any factor decreasing firms' profitability should shrink their incentive to invest, while the Arrovian position claims the opposite. The simplest way of formulating this alternative view of the issue at hand consists in taking the number of firms (i.e., industry structure) as given and then assess the consequences of quantity versus price competition on innovation efforts.

Irrespective of the nature of innovation (either for cost reductions or for the introduction of new products), a large theoretical literature attains either Schumpeterian or Arrovian conclusions (for exhaustive accounts, see Tirole, 1988; Reinganum, 1989; and Martin, 2002). ${ }^{1}$ That is, partial equilibrium theoretical IO models systematically predict a monotone relationship between aggregate R\&D efforts and industry structure, in either direction.

A completely different picture arises if one takes instead the standpoint of modern growth theory à la Aghion and Howitt (1998). In particular, Aghion et al. (2005) stress that empirical evidence shows a non-monotone relationship between industry concentration (or, the intensity of market competition) and aggregate R\&D efforts: this takes the form of an inverted- $U$ curve, at odds with all existing theoretical IO models; in the same paper, the authors provide a model yielding indeed such a concave result, and fitting the data. A thorough discussion, accompanied by an exhaustive review of the related

\footnotetext{
${ }^{1}$ See also Gilbert (2006), Vives (2008) and Schmutzler (2010) for add-on's on this discussion, where still the Schumpeter vs Arrow argument remains unresolved.
} 
lively debate, can be found in Aghion et al. (2013).

One could say that the inverted-U emerging from data says that Arrow is right for small numbers, while Schumpeter is right thereafter. Alternatively, on the same basis one could also say that neither Arrow nor Schumpeter can match reality, if our interpretation of their respective views is that "competition (resp., monopoly) outperforms monopoly (resp., competition) along the R\&D dimension." Be that as it may, there arises the need of constructing models delivering a non-monotone relationship between some form of investments in innovation, productive capacity or other relevant dimensions, and the number of firms in the industry.

One such dimension is advertising expenditure. Nerlove and Arrow (1962) pointed out that advertising expenditure should be treated in the same way as investment in a durable good. They assumed that there is a stock of goodwill that determines the current level of market demand. This stock of goodwill incorporates the advertising carried out in the past and, like capital stock, depreciates over time. This has generated a large literature extending their seminal contributions in several directions, indeed too many to be summarised here (see, e.g., Feichtinger et al., 1994; Erickson, 2004; Jørgensen and Zaccour, 2004; and Huang et al., 2012, for comprehensive surveys). A comparatively smaller number of contributions deal with oligopoly models (see Pauwels, 1977; Friedman, 1983; Fershtman, 1984; Erickson, 1995; Cellini and Lambertini, 2003a,b, inter alia) and either disregard the influence of industry structure on aggregate advertising expenditure or find a monotone relationship.

In this paper, we develop a dynamic oligopoly model of advertising to revisit the discussion between Arrow and Schumpeter looking at the firms' efforts to increase goodwill or brand equity. Firms are single-product units and sell differentiated varieties of the same good, investing in advertising to increase goodwill over an infinite horizon. Market competition takes place in outputs or prices, alternatively, and the game is fully noncooperative. All of this allows us to revisit the vexata quaestio of the relationship between investment incentives and market power/profitability in both the aforementioned ways. Our results can be spelled out as follows. First, the open-loop Nash equilibrium is strongly time consistent (i.e., subgame perfect) under both Cournot and Bertrand behaviour. Second, the relationship between the equilibrium aggregate advertising expenditure and the number of firms is concave and single-peaked, so that an inverted-U curve indeed arises, again irrespective of the market variable, provided that the degree of product dif- 
ferentiation is sufficiently high. Third, individual and aggregate advertising investments are higher in the Cournot setup then in the Bertrand one. Hence, under this respect, the flavour of the model is Schumpeterian.

The remainder of the paper is organised as follows. The model is laid out in section 2. Section 3 investigates the game under quantity-setting behaviour, while price-setting behaviour is considered in section 4. Concluding remarks are in section 5 .

\section{The setup}

Consider an industry existing over continuous time $t \in[0, \infty)$, populated by a set $N \equiv\{1,2,3, \ldots n\}$ of a priori fully symmetric single-product firms. Each of them uses the same productive technology characterised by a constant marginal cost (normalised to zero for simplicity) to supply a differentiated variety, whose instantaneous demand function is ${ }^{2}$

$$
p_{i}(t)=a-q_{i}(t)-s Q_{-i}(t)
$$

where $Q_{-i}(t)=\sum_{j \neq i} q_{j}(t)$ is the instantaneous output of rivals and $a>c$ and $s \in[0,1]$ are constant parameters. In particular, $s$ measures the degree of substitutability between any pair of varieties. In the special case $s=$ 0 , all varieties are independent of each other and all firms behave as pure monopolists in $N$ fully isolated markets. The inverse demand functions in (1) are for the Cournot (quantity-setting) game, while in the Bertrand (pricesetting) case one has to specify the direct demand system as follows:

$$
q_{i}(t)=\frac{a}{1+s(n-1)}-\frac{[1+s(n-2)] p_{i}(t)-s \sum_{j \neq i} p_{j}(t)}{(1-s)[1+s(n-1)]} .
$$

The instantaneous profits of the individual firm are

$$
\pi_{i}(t)=G_{i}(t)\left[a-q_{i}(t)-s Q_{-i}(t)\right] q_{i}(t)-b k_{i}^{2}(t),
$$

where $G_{i}(t)$ is a state variable representing the goodwill or brand equity associated with variety $i$. Firm $i$ 's brand equity is (i) positively affected by the

\footnotetext{
${ }^{2}$ This demand structure is generated by a linear-quadratic utility function of the representative consumer, as in Singh and Vives (1984), where only duopoly is considered. For the extension to oligopoly, see Vives (1985), Ottaviano et al. (2002) and Cellini et al. (2004), inter alia.
} 
advertising campaign, whose intensity is measured here by the instantaneous advertising effort $k_{i}(t)$, entailing a cost $\Gamma_{i}(t)=b k_{i}^{2}(t), b>0$; and (ii) negatively affected by the rival's collective effort $K_{-i}(t)=\sum_{j \neq i} K_{j}(t)$, so that the state dynamics writes as follows:

$$
\dot{G}_{i} \equiv \frac{d G_{i}(t)}{d t}=k_{i}(t)-\beta K_{-i}(t)-\delta G_{i}(t),
$$

in which parameter $\beta \in[0,1 /(n-1)]$ scales the negative spillover effect exerted by the $n-1$ rivals of firm $i$, in such a way that if $\beta=1 /(n-1)$, the spillover neutralizes altogether firm $i$ 's effort. Parameter $\delta>0$ is the goodwill decay rate, assumed constant and common to all varieties. Also constant and symmetric across the whole population of firms is taken to be the discount rate $\rho>0$.

Hence, each firm has two controls, the advertising effort and a market variable, either price or quantity, so that the game features $n$ states and $2 n$ controls. The objective of firm $i$ is to maximise the discounted profit flow

$$
\Pi_{i}(t) \equiv \int_{0}^{\infty} \pi_{i}(t) e^{-\rho t} d t
$$

subject to the set of dynamic constraints (4) and initial conditions $G_{i 0}=$ $G_{i}(0)>0$, plus the set of the appropriate transversality conditions to be specified in the remainder. Independently of the market variable being set, firms move simultaneously at all times, the solution concept being thus the Nash equilibrium under open-loop information. The reason for the choice of open-loop rules will become clear in the remainder.

\section{The Cournot game}

Under quantity-setting behaviour, the relevant demand structure is (1). As a result, the current-value Hamiltonian of firm $i$ is

$$
\mathcal{H}_{i}(t)=e^{-\rho t}\left\{\pi_{i}(t)+\lambda_{i i}(t) \dot{G}_{i}(t)+\sum_{j \neq i} \lambda_{i j}(t) \dot{G}_{j}(t)\right\},
$$

where $\lambda_{i j}(t)=\mu_{i j}(t) e^{\rho t}$ is the costate variable (evaluated at time $t$ ) associated with the state variable $G_{j}(t)$. We shall omit from now on the time 
argument when no ambiguity may arise. From (6) we can derive the first order conditions (FOCs) on controls: ${ }^{3}$

$$
\begin{gathered}
\frac{\partial \mathcal{H}_{i}}{\partial q_{i}}=G_{i}\left(a-2 q_{i}-s Q_{-i}\right)=0, \\
\frac{\partial \mathcal{H}_{i}}{\partial k_{i}}=-2 b k_{i}+\lambda_{i i}-\beta \sum_{j \neq i} \lambda_{i j}(t)=0,
\end{gathered}
$$

and the set of co-state equations:

$$
\begin{gathered}
\dot{\lambda}_{i i}=-\frac{\partial \mathcal{H}_{i}}{\partial G_{i}}+\rho \lambda_{i i} \Leftrightarrow \\
\dot{\lambda}_{i i}=(\delta+\rho) \lambda_{i i}-q_{i}\left(a-q_{i}-s Q_{-i}\right), \\
\dot{\lambda}_{i j}=-\frac{\partial \mathcal{H}_{i}}{\partial G_{j}}+\rho \lambda_{i j} \Leftrightarrow \dot{\lambda}_{i j}=(\delta+\rho) \lambda_{i j} .
\end{gathered}
$$

The accompanying set of transversality conditions is $\lim _{t \rightarrow \infty} \lambda_{i j} G_{j} e^{-\rho t}=0$ for all $i, j=1,2, \ldots, n$.

Before proceeding any further, note that (10) admits the solution $\lambda_{i j}=0$ at all times, and therefore (7-9) imply that the open-loop Nash solution is indeed subgame perfect as it is a degenerate feedback equilibrium. ${ }^{4}$ More formally, we can formulate this result in the following: ${ }^{5}$

Lemma 1 The open-loop information structure gives rise to a strongly time consistent equilibrium.

Then, we can impose symmetry across variables, thus rewriting (7-9) as

$$
\begin{gathered}
G[a-q(1+s(n-1))]=0, \\
\lambda-2 b k=0,
\end{gathered}
$$

\footnotetext{
${ }^{3}$ Henceforth we will omit the explicit indication of the time argument for the sake of brevity.

${ }^{4}$ For more on the arising of strongly time consistent equilibria in differential games solved under open-loop information, see Fershtman (1987), Mehlmann (1988, ch. 4), Dockner et al. (2000, ch. 7) and Cellini et al. (2005).

${ }^{5}$ The analysis of the feedback equilibrium based on the Hamilton-Jacoby-Bellman equation of the Cournot game is in the Appendix. It shows that indeed the feedback equilibrium degenerates into the open-loop one illustrated here.
} 


$$
\dot{\lambda}=(\delta+\rho) \lambda-q[a-q(1+s(n-1))] .
$$

Now notice that (11) admits the quasi-static solution

$$
q_{C N}^{*}=\frac{a}{1+s(n-1)}
$$

replicating the static Cournot-Nash output (whence the subscript). Equations (12-13) can be manipulated to derive the control equation

$$
\dot{k}=\frac{\dot{\lambda}}{2 b}=(\delta+\rho) \lambda-q[a-q(1+s(n-1))],
$$

so that, using $\lambda=2 b k$ and (14), the dynamics of the advertising effort is described by

$$
\dot{k}=\frac{2 b k(\delta+\rho)[2+s(n-1)]^{2}-a^{2}}{2 b[2+s(n-1)]^{2}},
$$

which, together with

$$
\dot{G}=k[1-\beta(n-1)]-\delta G,
$$

forms the state-control dynamic system of the present formulation of the game. Imposing stationarity on (16-17), we obtain the coordinates of the unique steady-state-equilibrium point

$$
k_{C N}^{*}=\frac{a^{2}}{2 b(\delta+\rho)[2+s(n-1)]^{2}} ; G_{C N}^{*}=\frac{k_{C N}^{*}[1-\beta(n-1)]}{\delta} .
$$

Note that $G_{C N}^{*}$, which is non-negative for all admissible values of $\beta$, corresponds to

$$
\lim _{t \rightarrow \infty} G_{C N}(t)=e^{-\delta t} G_{0}+k_{C N}^{*}[1-\beta(n-1)]\left(1-e^{-\delta t}\right) .
$$

The foregoing analysis can be summarised in

Proposition 2 The open-loop advertising game associated with Cournot competition produces a unique steady-state-equilibrium point at $\left\{G_{C N}^{*}, k_{C N}^{*}, q_{C N}^{*}\right\}$, which is subgame perfect.

Moreover, the stability analysis of the system (16-17) can be easily performed to prove: 
Proposition 3 The steady-state equilibrium $\left\{G_{C N}^{*}, k_{C N}^{*}, q_{C N}^{*}\right\}$ is a saddle point.

Proof. It suffices to observe that the determinant of Jacobian matrix associated with the dynamic system $(16-17)$ is $\Delta=-\delta(\delta+\rho)<0$.

We are now in a position to tackle the main issue we are interested with, namely, the shape of the equilibrium advertising effort at the industry level, $K_{C N}^{*}=n k_{C N}^{*}$, whose main features are captured by the following partial derivatives:

$$
\begin{aligned}
\frac{\partial K_{C N}^{*}}{\partial n} & =\frac{a^{2}[s(n+1)-2]}{2 b(\delta+\rho)[2+s(n-1)]^{2}}, \\
\frac{\partial^{2} K_{C N}^{*}}{\partial n^{2}} & =\frac{a^{2}[s(n+2)-4]}{b(\delta+\rho)[2+s(n-1)]^{4}} .
\end{aligned}
$$

Solving $\partial K_{C N}^{*} / \partial n=0$, we have

$$
n_{C N}=\frac{2-s}{s} \geq 2 \forall s \in\left[0, \frac{2}{3}\right],
$$

in correspondence of which (21) is negative. Accordingly, we may claim

Proposition 4 For all $s \in[0,2 / 3]$, the aggregate advertising effort $K_{C N}^{*}$ is concave and single-peaked in the number of firms, taking its maximum at $n_{C N}=(2-s) / s \geq 2$.

The above result says that a sufficiently high degree of product differentiation delivers an inverted-U aggregate advertising effort at equilibrium. This claim can be complemented by the ancillary observation that $n_{C N}=1$ in correspondence of $s=1$, i.e., if products are perfect substitutes, then the model takes a Schumpeterian flavour, as it happens for all $s \in(2 / 3,1]$ : if varieties are too little differentiated, aggregate equilibrium investment decreases monotonically in the number of firms.

\section{The Bertrand game}

Under price-setting behaviour, (2) replaces (1). The Hamiltonian function of firm $i$ is:

$$
\mathcal{H}_{i}=e^{-\rho t}\left\{G_{i}\left[\frac{a}{1+s(n-1)}-\frac{[1+s(n-2)] p_{i}-s \sum_{j \neq i} p_{j}}{(1-s)[1+s(n-1)]}\right] p_{i}\right.
$$




$$
\left.-b k_{i}^{2}+\lambda_{i i} \dot{G}_{i}+\sum_{j \neq i} \lambda_{i j} \dot{G}_{j}\right\}
$$

which generates the following set of necessary conditions:

$$
\begin{gathered}
\frac{\partial \mathcal{H}_{i}}{\partial p_{i}}=\frac{G_{i}\left[a(1-s)-2(1+s(n-2)) p_{i}+s \sum_{j \neq i} p_{j}\right]}{(1-s)[1+s(n-1)]}=0, \\
\frac{\partial \mathcal{H}_{i}}{\partial k_{i}}=-2 b k_{i}+\lambda_{i i}-\beta \sum_{j \neq i} \lambda_{i j}=0,
\end{gathered}
$$

and the set of co-state equations:

$$
\begin{gathered}
\dot{\lambda}_{i i}=-\frac{\partial \mathcal{H}_{i}}{\partial G_{i}}+\rho \lambda_{i i} \Leftrightarrow \\
\dot{\lambda}_{i i}=(\delta+\rho) \lambda_{i i}-\frac{p_{i}\left[a(1-s)-(1+s(n-2)) p_{i}+s \sum_{j \neq i} p_{j}\right]}{(1-s)[1+s(n-1)]}, \\
\dot{\lambda}_{i j}=-\frac{\partial \mathcal{H}_{i}}{\partial G_{j}}+\rho \lambda_{i j} \Leftrightarrow \dot{\lambda}_{i j}=(\delta+\rho) \lambda_{i j},
\end{gathered}
$$

with the same transversality conditions as above. Once again, (27) admits $\lambda_{i j}=0$ at all $t \in[0, \infty)$, and the open-loop solution is strongly time consistent. Proceeding in the same manner as in the previous section, we obtain the Bertrand-Nash equilibrium price

$$
p_{B N}^{*}=\frac{a(1-s)}{2+s(n-3)}>0 \forall s \in[0,1),
$$

which collapses onto marginal cost if the good is homogeneous, and the control equation

$$
\dot{k}=\frac{2 b k(\delta+\rho)[2+s(n-3)]^{2}[1+s(n-1)]-a^{2}(1+s)[1+s(n-2)]}{2 b[2+s(n-3)]^{2}[1+s(n-1)]},
$$

which, together with (17), constitutes the state-control system relevant for the Bertrand case. The unique stationary point of the system (17-29) is

$$
k_{B N}^{*}=\frac{a^{2}(1-s)[1+s(n-2)]}{2 b(\delta+\rho)[2+s(n-3)]^{2}[1+s(n-1)]} ; G_{B N}^{*}=\frac{k_{B N}^{*}[1-\beta(n-1)]}{\delta},
$$


where $G_{B N}^{*} \geq 0$ is the level at which the goodwill trajectory

$$
G_{B N}(t)=e^{-\delta t} G_{0}+k_{B N}^{*}[1-\beta(n-1)]\left(1-e^{-\delta t}\right),
$$

leads in steady state. It can be easily shown that (30) is a saddle point equilibrium (the proof is omitted for brevity).

The steady-state advertising effort of the entire industry is $K_{B N}^{*}=n k_{B N}^{*}$, whose partial derivative with respect to $n$ is

$$
\frac{\partial K_{B N}^{*}}{\partial n}=\Theta \cdot \frac{2+3 s(n-3)+s^{2}(13-7 n)-s^{3}\left[n^{2}(n-1)-2(2 n-3)\right]}{2 b(\delta+\rho)[2+s(n-1)]^{2}},
$$

where $\Theta \equiv a^{2}(1-s) /[2 b(\delta+\rho)]$. Hence we are interested in solving

$$
\begin{aligned}
& 2+3 s(n-3)+s^{2}(13-7 n)-s^{3}\left[n^{2}(n-1)-2(2 n-3)\right]= \\
& 2-s[9+s(13-6 s)]+n[3+(4 s-7) s] s+n^{2} s^{3}-n^{3} s^{3}=0
\end{aligned}
$$

Now define $\sigma \equiv s^{3}, \gamma \equiv 2-s[9+s(13-6 s)]$ and $\phi \equiv[3+(4 s-7) s] s$, so that (33) can be rewritten as

$$
-\sigma n^{3}+\sigma n^{2}+\phi n+\gamma=0
$$

which can be treated geometrically, knowing that $\sigma>0$ for all $s \in[0,1) ; \phi>$ 0 for all $s \in[0,3 / 4)$ and negative elsewhere; and $\gamma<0$ for all $s \in(1 / 2,2 / 3)$ and positive elsewhere.

The first step consists in observing that any $n$ solving (34) also solves

$$
\sigma n^{2}-\sigma n-\phi=\frac{\gamma}{n}
$$

so that the roots of $\partial K_{B N}^{*} / \partial n=0$ are identified by the intersections of the following system:

$$
\begin{gathered}
y_{1}=\sigma n^{2}-\sigma n-\phi, \\
y_{2}=\frac{\gamma}{n},
\end{gathered}
$$

i.e., the critical values of $n$, if they exist, are identified by the intersections - if any - of the parabola $y_{1}$ and the hyperbola $y_{2}$. First, observe that $y_{1}$ is convex for all $s \in(0,1]$; moreover, $y_{1}=\sigma n^{2}-\sigma n-\phi=0$ at

$$
n_{ \pm}=\frac{1}{2}\left(1 \pm \sqrt{\frac{\sigma+4 \phi}{\sigma}}\right)
$$


with $n_{-}<1$ for all $s \in[0,1]$ and $n_{+} \geq 2$ for all $s \in[0,1 / 2]$. Secondly, $y_{1}$ takes its minimum in correspondence of

$$
\frac{\partial y_{1}}{\partial n}=(2 n-1) \sigma=0,
$$

i.e., in $n=1 / 2$, which entails that $y_{1}$ is increasing for all $n \geq 1$. Thirdly, $y_{2}>$ 0 for all $s \in(0,1]$ and $y_{2} \geq y_{1}$ for all $s \in[0,1 / 2]$. Finally, $\partial K_{B N}^{*} /\left.\partial n\right|_{n=1}=$ $1 / 4$ irrespective of the value of $s$. The latter observation, in particular, entails that if a unique intersection does occur at some $n_{N B} \geq 2$, then it is a maximum point and we can disregard the sign of $\partial^{2} K_{B N}^{*} / \partial n^{2}$ as it is surely negative. These properties jointly establish the following result:

Proposition $5 s \in[0,1 / 2]$ is a sufficient condition for $\partial K_{B N}^{*} / \partial n$ to be nil in correspondence of a unique number $n_{N B} \geq 2$. At such $n_{N B}, \partial^{2} K_{B N}^{*} / \partial n^{2}<0$ because $\partial K_{B N}^{*} /\left.\partial n\right|_{n=1}>0$.

In order to single out the necessary condition one must carry out some numerical calculations. It turns out that

$$
\left.K_{B N}^{*}\right|_{n=1}>\left.K_{B N}^{*}\right|_{n=2} \forall s \in(0.618,1] .
$$

and conversely in the complementary range of the key parameter $s$. Accordingly, we can formulate:

Proposition 6 The parameter range wherein Bertrand behaviour generates an inverted-U-shaped aggregate advertising effort at the steady state equilibrium is a proper subset of the range wherein Cournot behaviour yields the same result.

Hence, under both quantity- and price-setting behaviour, there emerges an inverted-U curve describing aggregate investment in goodwill at the steadystate equilibrium provided differentiation is sufficiently high. Accordingly, one can say that the concave shape of industry investments is robust to a change in market variables. However, the requirement on the level of product differentiation is milder in the Cournot model, intuitively because - Cournot competition being less aggressive, and consequently its profits higher than Bertrand's - quantity-setting behaviour more easily allow for the balance between the competitive effect (Schumpeter) and the replacement effect (Arrow) to flip over at some $n>1$. 
As a last step, we may compare aggregate steady state investments to find that

$$
K_{C N}^{*}-K_{B N}^{*}=\frac{a^{2}(n-1)^{2} n s^{3}[2+s(n-2)]}{2 b(\delta+\rho)[2+s(n-3)]^{2}[1+s(n-1)][2+s(n-1)]^{2}}>0,
$$

for all $n>1$ and $s \in(0,1]$. Moreover,

$$
\begin{aligned}
G_{C N}(t)-G_{B N}(t) & =\frac{[1-(n-1) \beta]\left(1-e^{-\delta t}\right)}{\delta}\left(k_{C N}^{*}-k_{B N}^{*}\right) \geq 0, \\
G_{C N}^{*}-G_{B N}^{*} & =\frac{[1-(n-1) \beta]}{\delta}\left(k^{C}-k^{B}\right) \geq 0 .
\end{aligned}
$$

So, if one interprets the Schumpeterian hypothesis in the sense that any reduction in the intensity of competition must be expected to foster investments, for example by choosing quantity-setting rather than price-setting strategies for any degree of substitutability, then (40) shows that Schumpeter was right:

Proposition 7 Cournot competition enhances equilibrium individual and collective advertising efforts as compared to Bertrand competition. The resulting individual and collective amount of goodwill is higher under quantity-setting behaviour.

The explanation appears to be that since quantity strategies are less aggressive than price strategies, and the corresponding gross profits react accordingly, a fully Schumpeterian argument applies: the size of profits definitely matter. There remain to be assessed the consequences on social welfare, which are however intuitive and can be quickly dealt with, since the above proposition clearly implies that welfare is higher under Bertrand competition (welfare - gross of advertising costs - is higher under Bertrand competition; hence, a fortiori, it is higher than that generated by Cournot after subtracting total advertising costs).

\section{Concluding remarks}

We have characterised the effects of industry structure and market competition on individual and aggregate advertising efforts in a differential oligopoly 
game in which firms sell differentiated varieties of the same good. Irrespective of whether firms are quantity- or price-setting agents, an inverted Ushaped aggregate investment curve emerges at equilibrium, if varieties are sufficiently differentiated. This is in line with recent empirical and theoretical results (Aghion et al., 2005) shedding new light on the long-standing debate between Schumpeter and Arrow. A Schumpeterian flavour instead characterises the bearings of market competition on individual and aggregate advertising expenditure, as the latter is higher under Cournot competition, for any industry structure. 


\section{Appendix}

What follows illustrates the feedback solution of the game in which firms set output levels. Observe that each player's payoff and dynamics depend only on her own goodwill. (There is of course an indirect dependence through the control variables of the other players.) Denote by $V_{i}\left(G_{i}\right)$ the value function of player $i$. The Hamilton-Jacobi-Bellman (HJB) equation of this player reads as follows:

$$
\rho V_{i}\left(G_{i}\right)=\max _{q_{i}, k_{j}}\left\{G_{i}\left(a-q_{i}-s Q_{-i}\right) q_{i}-b k_{i}^{2}+V_{i}^{\prime}\left(G_{i}\right)\left(k_{i}-\beta K_{-i}-\delta G_{i}\right)\right\} .
$$

Assuming an interior solution, from the necessary conditions for optimality taking the partial derivatives of the RHS in (a1) with respect to $q_{i}$ and $k_{i}$ and equating to zero, we obtain:

$$
\begin{aligned}
G_{i}\left(a-2 q_{i}-s Q_{-i}\right) & =0, \\
-2 b k_{i}+V_{i}^{\prime}\left(G_{i}\right) & =0 .
\end{aligned}
$$

The first condition shows that the quantities are strategic substitutes, that is, $\partial q_{i} / \partial q_{j}<0$, which is a feature of Cournot model. The second condition states that advertising strategy is determined by the familiar rule of marginal cost $\left(2 b k_{i}\right)$ being equal to marginal benefit, measured by the marginal value of goodwill $V_{i}^{\prime}\left(G_{i}\right)$.

As the model's parameters are identical for all players, it is intuitively appealing to look for a symmetric equilibrium. The ensuing analysis shows that the solution of the HJB equation (a1) indeed delivers the same outcome as the open-loop formulation of the same problem investigated in the main text.

Assume $G_{i}(t) \neq 0$ for all $i \in N$ and all $t \in[0, \infty)$. In a symmetric equilibrium, $q_{i}=q, k_{i}=k$ and $G_{i}=G$ for all $i \in N$. We conjecture that the value function of player $i$ is linear and given by $V(G)=\mathcal{C}+\mathcal{D} G$. The equilibrium conditions (a2-a3) become

$$
\begin{aligned}
q & =\frac{a}{2+s(n-1)}=q_{C N}^{*}, \\
k & =\frac{\mathcal{D}}{2 b} .
\end{aligned}
$$


Inserting (a4-a5) in (a1) yields

$$
\begin{aligned}
\rho V(G) & =G(a-q-s(n-1)) q-b k^{2}+V^{\prime}(G)(k-\beta(n-1) k-\delta G), \\
\rho(\mathcal{C}+\mathcal{D} G) & =\frac{a^{2} G}{(2+s(n-1))^{2}}+\frac{\mathcal{D}^{2}}{4 b}([1-2 \beta(n-1)])-\delta \mathcal{D} G .
\end{aligned}
$$

By identification, we have

$$
\begin{aligned}
\mathcal{D} & =\frac{a^{2}}{(\rho+\delta)(2+s(n-1))^{2}}, \\
\mathcal{C} & =\frac{a^{4}(1-2 \beta(n-1))}{4 \rho b(\rho+\delta)^{2}(2+s(n-1))^{4}}
\end{aligned}
$$

Using $k=\mathcal{D} /(2 b)$, we obtain

$$
k=\frac{a^{2}}{2 b(\delta+\rho)(2+s(n-1))^{2}}=k_{C N}^{*} .
$$

The value function is linear and given by

$$
V_{C N}(G)=\frac{a^{2}}{(\rho+\delta)(2+s(n-1))^{2}}\left(\frac{a^{2}(1-2 \beta(n-1))}{4 \rho b(\rho+\delta)(2+s(n-1))^{2}}+G\right)
$$

The above results call for the following two observations:

1. The analysis of the feedback game has been carried out under the assumptions that the solution is interior, which obviously holds true, and the goodwill stock is never equal to zero. Substituting for the advertising strategies in the goodwill dynamics and solving the differential equation yields the trajectory

$$
G_{C N}(t)=e^{-\delta t} G_{0}+\frac{a^{2}(1-(n-1) \beta)}{2 b \delta(\delta+\rho)(2+s(n-1))^{2}}\left(1-e^{-\delta t}\right) .
$$

Under our specification that $\beta \in[0,1 /(n-1)]$,we clearly have $G(t) \geq$ 0 for all $t \in[0, \infty)$. The steady-state value is given by

$$
G_{C N}^{*}=\frac{a^{2}(1-(n-1) \beta)}{2 b \delta(\delta+\rho)(2+s(n-1))^{2}}>0 .
$$


2. The result that the quantity and advertising strategies are independent of the state (i.e., constant or degenerate feedback) is surprising. Indeed, we would have expected this to occur if the differential game were of the linear-state variety, but this is not the case here. (In fact, the game is not even linear quadratic). This result has surely something to do with two facts: (i) the other players' state variables do not appear in each player's optimization problem; and (ii) the multiplicative form in $G$ of the revenue function. In any event, with constant strategies, we conclude that open-loop and Markov-perfect Nash equilibria coincide. Interestingly, this implies that the characterization of the entire industry's advertising effort is indeed independent of the information structure.

The feedback solution of the Bertrand game confirms the same conclusions reached in the Cournot setting (namely, that the open-loop equilibrium is a degenerate feedback one) and is omitted for brevity. 


\section{References}

[1] Aghion, P. and P. Howitt. (1998), Endogenous Growth Theory, Cambridge, MA, MIT Press.

[2] Aghion, P., U. Akcigit and P. Howitt (2013), "What Do We learn from Schumpeterian Growth Theory?", mimeo, Department of Economics, Harvard University.

[3] Aghion, P., N. Bloom, R. Blundell, R. Griffith and P. Howitt (2005), "Competition and Innovation: An Inverted-U Relationship", Quarterly Journal of Economics, 120, 701-28.

[4] Arrow, K. (1962), "Economic Welfare and the Allocation of Resources for Invention", in R. Nelson (ed.), The Rate and Direction of Industrial Activity, Princeton, NJ, Princeton University Press.

[5] Bagwell, K. (2007), "The Economic Analysis of Advertising", in M. Armstrong and R. Porter (eds), Handbook of Industrial Organization, vol. III, Amsterdam, North-Holland.

[6] Cellini, R. and L. Lambertini (2003a), "Advertising in a Differential Oligopoly Game", Journal of Optimization Theory and Applications, 116, 61-81.

[7] Cellini, R. and L. Lambertini (2003b), "Advertising with Spillover Effects in a Differential Oligopoly Game with Differentiated Goods", Central European Journal of Operations Research, 11, 409-23.

[8] Cellini, R., L. Lambertini and G. Leitmann (2005), "Degenerate Feedback and Time Consistency in Differential Games", in E.P. Hofer and E. Reithmeier (eds), Modeling and Control of Autonomous Decision Support Based Systems. Proceedings of the 13th International Workshop on Dynamics and Control, Aachen, Shaker Verlag, 185-92.

[9] Cellini, R., L. Lambertini and G. Ottaviano (2004), "Welfare in a Differentiated Oligopoly with Free Entry: A Cautionary Note", Research in Economics, 58, 125-33.

[10] Dockner, E.J, S. Jørgensen, N. Van Long and G. Sorger (2000), Differential Games in Economics and Management Science, Cambridge, Cambridge University Press. 
[11] Doraszelski, U. and S. Markovich (2007), Advertising Dynamics and Competitive Advantage", RAND Journal of Economics, 38, 557-92.

[12] Erickson, G. (1995), "Differential Game Models of Advertising Competition", European Journal of Operational Research, 83, 431-38.

[13] Erickson, G. (2003), Dynamic Models of Advertising Competition. Second Edition, Dordrecht, Kluwer.

[14] Feichtinger, G., R. Hartl and S. Sethi (1994), "Dynamic Optimal Control Models in Advertising: Recent Developments", Management Science, 40, 195-226.

[15] Fershtman, C. (1984), "Goodwill and Market Shares in Oligopoly", Economica, 51, 271-81.

[16] Fershtman, C. (1987), "Identification of Classes of Differential Games for Which the Open-Loop is a Degenerated Feedback Nash Equilibrium", Journal of Optimization Theory and Applications, 55, 217-31.

[17] Friedman, J.W. (1983), "Advertising and Oligopolistic Equilibrium", Bell Journal of Economics, 14, 464-73.

[18] Gilbert, R. (2006), "Looking for Mr Schumpeter: Where Are We in the Competition-Innovation Debate?", in J. Lerner and S. Stern (eds), Innovation Policy and Economy, NBER, MIT Press.

[19] Huang, J., M. Leng and L. Liang (2012), "Recent Developments in Dynamic Advertising Research", European Journal of Operational Research, 220, 591-609.

[20] Jørgensen, S. and G. Zaccour (2004), Differential Games in Marketing, Dordrecht, Kluwer.

[21] Martin, S. (2002), Advanced Industrial Economics. Second Edition, Oxford, Blackwell.

[22] Mehlmann, A. (1988), Applied Differential Games, New York, Plenum Press.

[23] Nerlove, M. and K. Arrow (1962), "Optimal Advertising Policy Under Dynamic Conditions", Economica, 29, 129-42. 
[24] Ottaviano, G.I.P., T. Tabuchi and J.-F. Thisse (2002), "Agglomeration and Trade Revisited", International Economic Review, 43, 409-36.

[25] Pauwels, W. (1977), "Optimal Dynamic Advertising Policies in the Presence of Continuously Distributed Time Lags", Journal of Optimization Theory and Applications, 22, 79-89.

[26] Reinganum, J. (1989), "The Timing of Innovation: Research, Development, and Diffusion", in R. Schmalensee and R.D. Willig (eds), Handbook of Industrial Orgaanization, vol. I, Amsterdam, North-Holland.

[27] Schmalensee, R. (1976), "A Model of Promotional Competition in Oligopoly", Review of Economic Studies, 43, 493-507.

[28] Schmutzler, A. (2010), "Is Competition Good for Innovation? A Simple Approach to An Unresolved Question", Foundations and Trends in Microeconomic Analysis, 5, 355-428.

[29] Schumpeter, J.A. (1934), The Theory of Economic Development, Oxford, Oxford University Press.

[30] Schumpeter, J.A. (1942), Capitalism, Socialism and Democracy, New York, Harper.

[31] Sethi, S. (1977), "Dynamic Optimal Control Models in Advertising: A Survey", SIAM Review, 19, 685-725.

[32] Singh, N. and X. Vives (1984), "Price and Quantity Competition in a Differentiated Duopoly", RAND Journal of Economics, 15, 546-54.

[33] Tirole, J. (1988), The Theory of Industrial Organization, Cambridge, MA, MIT Press.

[34] Vives, X. (1985), "Efficiency of Bertrand and Cournot Equilibria with Product Differentiation", Journal of Economic Theory, 36, 166-75.

[35] Vives, X. (2008), "Innovation and Competitive Pressure", Journal of Industrial Economics, 56, 419-69. 


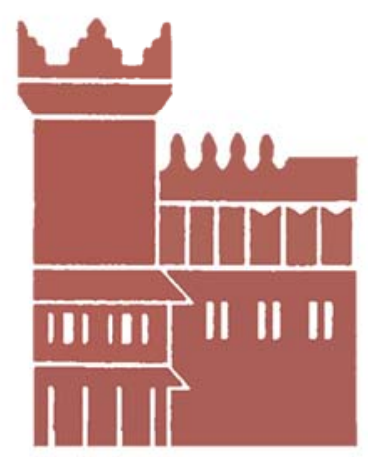

Alma Mater Studiorum - Università di Bologna DEPARTMENT OF ECONOMICS

Strada Maggiore 45

40125 Bologna - Italy

Tel. +39051 2092604

Fax +390512092664

http://www.dse.unibo.it 